\title{
Three percent annually on systemic glucocorticoids: facts, worries and perspectives
}

\author{
Onno C Meijer and Alberto M Pereira
}

Division of Endocrinology, Department of Medicine, Leiden University Medical Center, Leiden, The Netherlands

Correspondence should be addressed to O C Meijer

Email

o.c.meijer@lumc.nl

\begin{abstract}
A comprehensive study from Denmark established that the systemic use of glucocorticoids hormones has an annual prevalence of $3 \%$ and has been stable from 1999 to 2014. We comment on the risk of potentially long-lasting adverse effects, dependent on glucocorticoid receptor overactivation, but also mineralocorticoid receptor under-activation. We discuss the potential effects of glucocorticoid use on efficacy and toxicity of other drugs that are frequently taken concomitantly. We discuss the potential alternatives such as more selective targeting, and novel types of glucocorticoid receptor ligands. We conclude that pending improved therapies more conservative prescription of glucocorticoids may be warranted in clinical practice.
\end{abstract}

The case of the first glucocorticoid-treated patient is almost biblical, as we tell it to our students. A woman with severe rheumatoid arthritis, unable to move, is brought into the hospital. She gets treated with the experimental (pro-)drug cortisone and resurrects from her bed 3 days into the treatment. The Noble prize for the discovery and clinical use of glucocorticoids followed 2 years later (1). Since then many millions have been treated with synthetic glucocorticoids, mainly for their potent antiinflammatory effects but also to treat edema and to kill lymphoid cancers. Glucocorticoids have been beneficial to many, but also can come with a host of adverse effects, which may range from mild to life threatening (2).

How big a problem is the use of glucocorticoids? One may expect that as medical science progresses, there will be more drugs that treat diseases rather than their symptoms. For example, in rheumatic diseases, disease-modifying 'biologicals' that intervene early in the auto-immune process may be expected to lower the use of much less specifically acting drugs like glucocorticoids. This should be visible in the long-term trends of glucocorticoid use. On the other hand, there are many instances in which glucocorticoids will 'simply work', and/or there will be no good alternative. The long-term number of glucocorticoid users is what a recent nation-wide study from Denmark addressed.

Laugesen et al. made use of the very well-documented history of medical treatment in Denmark to describe all prescriptions for systemic (oral or injected) glucocorticoid use, over a period of 15 years (3). The authors describe among others the diseases and other drug prescriptions that accompany the use of systemic glucocorticoids. They counted almost 1 million cases during 1999-2014, which amounts to an annual prevalence of $3 \%$ of the population, with an incidence of $1.4 / 100$ person years. Glucocorticoid use increased substantially with age. These numbers were remarkably constant over the years, in spite of the increased use of disease-modifying drugs. If we translate these numbers to the European Union (508 million inhabitants), more than 15 million people are taking systemic glucocorticoids on an annual basis. Should we worry about these numbers in terms of adverse effects, and if so, how badly? The likely answers are that we should worry, but we do not know for how many

Published by Bioscientifica Ltd. 
patients, and we also still cannot correctly identify which patients are prone to adverse effects, as there are many aspects to consider.

\section{Effects}

The first aspect to consider is that the large number of adverse glucocorticoid effects makes perfect biological sense. The endogenous glucocorticoids in humans are cortisol (identical to hydrocortisone) and to some extent corticosterone (4). These hormones are made for bodywide action. Their basal circadian secretion pattern from the adrenal cortex supports circadian activity patterns, in part by acting as a synchronizing factor for the molecular clocks that are present in every cell of the body (5). On top of that, glucocorticoids are stress hormones and coordinate adaptation to acute and chronic stressors (6). This involves recruitment of energy stores from the liver and adipose tissue or driving behavioral decisions and memory formation by acting on the brain. The potent modulating effects on the immune system are also partly shaping the stress response, in case the stressor is an infection. The consequence of these many roles of the hormones is that the receptors need to be everywhere (7). Targeting any tissue with glucocorticoids will - save for local application - target many other cells and tissues.

\section{Receptors}

While clinical glucocorticoid treatment is exclusively aimed at activating the glucocorticoid receptor (GR), cortisol and corticosterone act via two receptor types: they bind to the GR, but with a ten-fold higher affinity also to the mineralocorticoid receptor (MR). MRs can be either aldosterone selective (e.g. in the kidney) or cortisol-preferring, depending on intracellular enzymatic conversion of cortisol into inert cortisone (8). Cortisolpreferring MRs are very prominent in the brain, but are also present in the heart (9) and in the immune system, where they can mediate pro-inflammatory effects of cortisol. Cortisol effects depend on the activation level of either receptor type, but sometimes also on the balance between MR and GR activation, particularly in the brain (6).

\section{Mineralocorticoid receptors}

The presence of two receptor types for cortisol is relevant for adverse effects of exogenous glucocorticoids. High concentrations of GR ligands that have sufficient residual MR activity may lead to the overactivation of MR. In contrast, highly selective GR agonists have the opposite effect. Because they strongly suppress endogenous cortisol secretion by activating negative feedback, they will lead to depletion of ligand for the cortisolpreferring MRs and render these inactive (10). A state of high GR activation and very low MR activation may be particularly relevant for the brain, where cortisol via MR is important for emotion regulation and aspects of sleep (11). Accordingly, simple add-on of cortisol could prevent neuropsychiatric side effects of selective GR agonists. Support for this hypothesis comes from a study in childhood leukemia for those children that experienced the most severe mood and sleep effects of the selective GR agonist dexamethasone (12).

Clinically used synthetic glucocorticoids all have different degrees of GR preference (13). Methylprednisolone and prednisolone account for $68 \%$ of systemic glucocorticoid use in the Danish study, and differ in MR potency from cortisol only by a factor 2-4. However, 25\% of systemic glucocorticoid prescriptions concerned betamethasone, which has much higher GR preference, and would therefore be predicted to lead to more sleep and mood disturbances via under-activation of brain MR.

\section{Glucocorticoid receptors}

Overactivation of GR is responsible for most of the adverse effects of glucocorticoid treatment. This depends strongly on the dose, duration and the compound that is used. Unfortunately, information on dosing is not available from the Danish study. For the most frequently used drug, prednisolone, a European task force for rheumatism stated that long-term dosing of $<5 \mathrm{mg}$ per day was without significant adverse effects, whereas doses $>10 \mathrm{mg}$ clearly did cause adverse effects (14). Of note, this study scored only for four main adverse effects (osteoporosis, hyperglycaemia/diabetes mellitus, cardiovascular diseases, and infections), with no robust evidence on the risk of harm on the long term. Stress resilience in daily life and emotional and cognitive functioning was not evaluated.

Besides cumulative exposure, the risk depends on patient characteristics. These include common genetic variation in the NR3C1 gene, coding for GR, leading to different receptor sensitivity (15). In rare cases, there may be real hypersensitivity, and patients may even develop adverse effects upon non-systemic treatment (16). Apart 
from intrinsic GR sensitivity, it is also true that outside basic animal research and pediatric endocrinology, a parameter like body weight (that is: pharmacokinetic volume of distribution) is very rarely taken into account, even in patients using assumed physiological hydrocortisone replacement for adrenal insufficiency $(17,18)$. In practice it is mostly unknown which patients are at risk for (particular) side effects, in case there is no comorbidity.

Mechanistically, GR overactivation can have direct consequences on the expression of hundreds of target genes in many cell types in the body. Deleterious effects follow straightforwardly from for example driving catabolic gene expression patterns in muscle (19) or from stimulating osteoclast function while inhibiting osteoblasts in bone. In this sense, endogenous Cushing's syndrome clearly shows the whole spectrum of possible morbidities, which may occur after exogenous glucocorticoid administration.

\section{Rhythms}

Apart from this 'mass action', the rhythmicity and reactivity that characterize endogenous cortisol secretion are partially lost under synthetic glucocorticoids. There is a clear circadian rhythm of cortisol secretion, which starts a few hours before awakening. Synthetic steroids activate negative feedback, mainly at the level of the pituitary, and suppress the endogenous production of cortisol. Enhanced negative feedback will affect stress responsiveness of the hypothalamus-pituitary-adrenal axis and may interfere with adaptation to stressors. Longacting steroids or steroids taken late during the day (as is sometimes necessary for glycemic control) may prevent the period of very low GR activation, which normally occurs during the evening and early night.

The work of Stafford Lightman emphasized beautifully that there is not only a circadian rhythm, but also an ultradian rhythm (20). The latter consists of pulses of adrenal hormone secretion with a period of around $2-3 \mathrm{~h}$ in humans. This rhythm is based on the intrinsic feedforward - feedback between the pituitary and the adrenal gland. Work in rodents and humans demonstrated that loss of ultradian rhythmicity substantially affects responses of emotional brain areas and that normal ultradian rhythm of glucocorticoids is a pre-requisite for optimal cognitive functioning $(21,22)$. In animal studies, the pattern of endogenous glucocorticoid exposure over the day was an independent factor that determined the cellular GR sensitivity (23). The relevance of absence of ultradian peaks for tissues other than the brain will be subject to further investigation.

\section{Long-term effects}

The occurrence of adrenal insufficiency that may persist for a time after cessation of glucocorticoid treatment is one example of potential long-term consequences of (chronic) use (24). From Cushing's patients we know that quality of life and cognitive function is impaired for many years after correction of cortisol excess (25). In fact, brain scans showed changes in gray and white matter of Cushings' patients more than 10 years after biochemical cure (26). This raises concerns for patients that were on high doses of synthetic glucocorticoids for prolonged periods of time, for example, in relation to vulnerability for psychological stressors.

In relation to long-term effects, there is a large, mainly basic science literature on the (epigenetic) consequences of early life (including intrauterine) glucocorticoid exposure, as a consequence of stress or maternal elevated cortisol $(26,27)$. Human studies on early life stress include effects on for example methylation levels of the FKBP5 gene, a modulator of glucocorticoid sensitivity (28). However, the evidence for glucocorticoids as mediators of early life stress effects is mostly lacking.

The question is then, whether long-term changes that do occur after exposure to high concentrations of glucocorticoids are irreversible. Intriguing animal studies showed that administration of the GR antagonist mifepristone weeks to months after early life stressors could partially normalize the effects of stress $(29,30,31$, 32). This suggests that glucocorticoids were involved in the long-term stress effects. The data also demonstrate that some long-term consequences of overactivation of GR may be reversible. However, we will first have to firmly establish what those consequences are for the users of synthetic glucocorticoids.

\section{Drug interactions}

The Danish study suggests that the majority of steroid prescriptions happens in settings of multiple drugs, due to the high incidence in aged individuals. The apparently frequent co-medication raises the question what glucocorticoid use does for the efficacy and toxicity of other medication. By their very nature of being transcription factors, they often do not change the activity 
of differentiated cells, but rather their reactivity to other stimuli. Already 30 years ago, it became clear from animal studies that glucocorticoids affect the responsiveness of neurons: acute exposure to corticosterone suppressed the response of hippocampus neurons to noradrenaline (33). In the liver, insulin and cortisol antagonize each other's action (34). And then, there are many unknowns.

Of the other drugs, antibiotics were the most frequently used medication in the Danish study (49\% of the cases). These are targeted at non-human tissues, and interactions may 'just' be relevant in terms of immune balance. The authors themselves point out that there is an increased risk for gastrointestinal hemorrhage by the combination treatment NSAIDs glucocorticoids. Antidepressants (used in 13\% of the cases) are mostly targeted to increase the levels of serotonin and/or noradrenalin in the synapses. Chronic glucocorticoid treatment has been shown to suppress the response of hippocampus neurons to serotonin (35). Such interactions with neurotransmitters may interfere with the efficacy of antidepressant treatments. Other concerns include anti-coagulants (used by 16\% of the people taking glucocorticoids), antipsychotics and treatment for osteoporosis. It is likely that prescribers simply have no choice but to treat with drugs that partly oppose each other's action, but also that they are actually unaware of all the proven and potential risks.

\section{Alternatives}

The persistent high incidence of systemic glucocorticoid use, together with the established and potential adverse effects, indicate that alternatives would be welcome. More specific targeting of glucocorticoids to, for e.g., immune cells may be an option (36), but this strategy is at present not sufficiently developed. Another promise is that of selective GR modulators. These are drugs that act as agonist only on some downstream signaling pathways, and therefore, have fewer adverse effects (37). The notion of separating anti-inflammatory from other effects is more than 20 years old and although selective modulators have entered in clinical trials, this 'Holy Grail' of glucocorticoid research has not yet been found $(38,39,40,41,42,43,44,45)$. There are however recent developments that suggest that tissue- or cellularprocess-specific GR manipulation is indeed possible, and this is of great potential benefit for patients in need of glucocorticoid treatment $(40,41)$.

\section{Conclusion}

With 3\% annual prevalence, the use of systemic glucocorticoids is substantial and stable. Depending on dose and duration there are bound to be many adverse effects of these treatments. The type of steroid will determine whether or how MRs are involved in addition to the GRs that form the actual target of the drugs. Adverse effects may be long lasting, and in some cases, even irreversible. On top of direct adverse effects, there is a real risk that glucocorticoids will interfere with the efficacy of other drugs. More disease-modifying drugs should eventually reduce the frequency of systemic glucocorticoid use. In parallel, we have to hope for a rapid translation of basic concepts like more selective targeting and selective receptor modulation to clinical practice. And clinicians may of course tune down on in some cases too liberal use of glucocorticoids in case the remedy is worse than the disease.

Declaration of interest

OCM receives research funding from Corcept Therapeutics, Menlo Park, CA, USA.

\section{Funding}

Our work on glucocorticoid side effects is supported by ZON-MW grant 95105005.

\section{References}

1 Hench P. Effects of cortisone in the rheumatic diseases. Lancet 19502 483-484.

2 Judd LL, Schettler PJ, Brown ES, Wolkowitz OM, Sternberg EM, Bender BG, Bulloch K, Cidlowski JA, de Kloet ER, Fardet L, et al. Adverse consequences of glucocorticoid medication: psychological, cognitive, and behavioral effects. The American Journal of Psychiatry 2014171 1045-1051. (https://doi.org/10.1176/appi. ajp.2014.13091264)

3 Laugesen K, Jorgensen JOL, Petersen I \& Sørensen HT. Fifteen-year nationwide trends in systemic glucocorticoid drug use in Denmark. European Journal of Endocrinology 2019181 267-273. (https://doi. org/10.1530/EJE-19-0305)

4 Nixon M, Mackenzie SD, Taylor AI, Homer NZM, Livingstone DE, Mouras R, Morgan RA, Mole DJ, Stimson RH, Reynolds RM, et al. ABCC1 confers tissue-specific sensitivity to cortisol versus corticosterone: a rationale for safer glucocorticoid replacement therapy. Science Translational Medicine 20168 352ra109. (https://doi org/10.1126/scitranslmed.aaf9074)

5 Oster H, Challet E, Ott V, Arvat E, De Kloet ER, Dijk D-J, Lightman S, Vgontzas A \& van Cauter E. The functional and clinical significance of the 24-h rhythm of circulating glucocorticoids. Endocrine Reviews 201638 3-45. (https://doi.org/10.1210/er.2015-1080)

6 De Kloet ER, Joëls M \& Holsboer F. Stress and the brain: from adaptation to disease. Nature Reviews. Neuroscience 20056 463-475. (https://doi.org/10.1038/nrn1683) 
7 Sapolsky RM, Romero LM \& Munck AU. How do glucocorticoids influence stress responses? Integrating permissive, suppressive, stimulatory, and preparative actions. Endocrine Reviews 200021 55-89. (https://doi.org/10.1210/edrv.21.1.0389)

8 Chapman K, Holmes M \& Seckl J. 11ß-hydroxysteroid dehydrogenases: intracellular gate-keepers of tissue glucocorticoid action. Physiological Reviews 201393 1139-1206. (https://doi. org/10.1152/physrev.00020.2012)

9 Oakley RH, Cruz-Topete D, He B, Foley JF, Myers PH, Xu X, GomezSanchez CE, Chambon P, Willis MS \& Cislowski JA. Cardiomyocyte glucocorticoid and mineralocorticoid receptors directly and antagonistically regulate heart disease in mice. Science Signaling 201912 12(577):eaau9685. (https://doi.org/10.1126/scisignal. aau9685)

10 Karssen AM, Meijer OC, Berry A, Sanjuan Piñol R \& De Kloet ER. Low doses of dexamethasone can produce a hypocorticosteroid state in the brain. Endocrinology 2005146 5587-5595. (https://doi. org/10.1210/en.2005-0501)

11 Meijer OC \& De Kloet ER. A refill for the brain mineralocorticoid receptor: the benefit of cortisol add-on to dexamethasone therapy. Endocrinology 2017158 448-454. (https://doi.org/10.1210/en.20161495)

12 Warris LT, van den Heuvel-Eibrink MM, Aarsen FK, Pluijm SMF, Bierings MB, van den Bos C, Zwaan CM, Thygese HH, Tissing WJE, Veening MA, et al. Hydrocortisone as an intervention for dexamethasone-induced adverse effects in pediatric patients With acute lymphoblastic leukemia: results of a double-blind, randomized controlled trial. Journal of Clinical Oncology 201634 2287-2293. (https://doi.org/10.1200/JCO.2015.66.0761)

13 Grossmann C, Scholz T, Rochel M, Bumke-Vogt C, Oelkers W, Pfeiffer AFH, Diederich S \& Bähr V. Transactivation via the human glucocorticoid and mineralocorticoid receptor by therapeutically used steroids in CV-1 cells: a comparison of their glucocorticoid and mineralocorticoid properties. European Journal of Endocrinology 2004 151 397-406. (https://doi.org/10.1530/eje.0.1510397)

14 Strehl C, Bijlsma JWJ, de Wit M, Boers M, Caeyers N, Cutolo M, Dasgupta B, Dixon WG, Geenen R, Huizinga TWJ, et al. Defining conditions where long-term glucocorticoid treatment has an acceptably low level of harm to facilitate implementation of existing recommendations: viewpoints from an EULAR task force. Annals of the Rheumatic Diseases 201675 952-957. (https://doi.org/10.1136/ annrheumdis-2015-208916)

15 Manenschijn L, van den Akker ELT, Lamberts SWJ \& Van Rossum EFC. Clinical features associated with glucocorticoid receptor polymorphisms. An overview. Annals of the New York Academy of Sciences 20091179 179-198. (https://doi.org/10.1111/j.17496632.2009.05013.x)

16 Koper JW, Van Rossum EFC \& van den Akker ELT. Glucocorticoid receptor polymorphisms and haplotypes and their expression in health and disease. Steroids 201492 62-73. (https://doi. org/10.1016/j.steroids.2014.07.015)

17 Mah PM, Jenkins RC, Rostami-Hodjegan A, Newell-Price J, Doane A, Ibbotson V, Tucker GT \& Ross RJ. Weight-related dosing, timing and monitoring hydrocortisone replacement therapy in patients with adrenal insufficiency. Clinical Endocrinology 200461 367-375. (https://doi.org/10.1111/j.1365-2265.2004.02106.x)

18 Bornstein SR, Allolio B, Arlt W, Barthel A, Don-Wauchope A, Hammer GD, Husebye ES, Merke DP, Murad MH, Stratakis CA, et al. Diagnosis and treatment of primary adrenal insufficiency: an Endocrine Society clinical practice guideline. Journal of Clinical Endocrinology \& Metabolism 2016101 364-389. (https://doi. org $/ 10.1210 /$ jc.2015-1710)

19 Schakman O, Kalista S, Barbé C, Loumaye A \& Thissen JP. Glucocorticoid-induced skeletal muscle atrophy. International Journal of Biochemistry and Cell Biology 201345 2163-2172. (https://doi. org/10.1016/j.biocel.2013.05.036)
20 Lightman SL \& Conway-Campbell BL. The crucial role of pulsatile activity of the HPA axis for continuous dynamic equilibration. Nature Reviews. Neuroscience 201011 710-718. (https://doi.org/10.1038/ nrn2914)

21 Sarabdjitsingh RA, Conway-Campbell BL, Leggett JD, Waite EJ, Meijer OC, De Kloet ER \& Lightman SL. Stress responsiveness varies over the ultradian glucocorticoid cycle in a brain-regionspecific manner. Endocrinology 2010151 5369-5379. (https://doi. org/10.1210/en.2010-0832)

22 Kalafatakis K, Russell GM, Harmer CJ, Munafo MR, Marchant N, Wilson A, Brooks JC, Durant C, Thakrar J, Murphy P, et al. Ultradian rhythmicity of plasma cortisol is necessary for normal emotional and cognitive responses in man. Proceedings of the National Academy of Sciences of the United States of America 2018115 E4091-E4100. (https://doi.org/10.1073/pnas.1714239115)

23 Sarabdjitsingh RA, Isenia S, Polman A, Mijalkovic J, Lachize S, Datson NA, de Kloet ER \& Meijer OC. Disrupted corticosterone pulsatile patterns attenuate responsiveness to glucocorticoid signaling in rat brain. Endocrinology 2010151 1177-1186. (https:// doi.org/10.1210/en.2009-1119)

24 Broersen LHA, Pereira AM, Jørgensen JOL \& Dekkers OM. Adrenal insufficiency in corticosteroids use: systematic review and metaanalysis. Journal of Clinical Endocrinology \& Metabolism 2015100 2171-2180. (https://doi.org/10.1210/jc.2015-1218)

25 Broersen LHA, Andela CD, Dekkers OM, Pereira AM \& Biermasz NR. Improvement but no normalization of quality of life and cognitive functioning after treatment for Cushing's syndrome. Journal of Clinical Endocrinology \& Metabolism 2019 Epub. (https://doi. org/10.1210/jc.2019-01054)

26 Andela CD, van Haalen FM, Ragnarsson O, Papakokkinou E, Johannsson G, Santos A, Webb SM, Biermasz NR, van der Wee NJA \& Pereira AM. MECHANISMS IN ENDOCRINOLOGY: Cushing's syndrome causes irreversible effects on the human brain: a systematic review of structural and functional magnetic resonance imaging studies. European Journal of Endocrinology 2015173 R1-R14. (https://doi.org/10.1530/EJE-14-1101)

27 Hollanders JJ, Heijboer AC, van der Voorn B, Rotteveel J \& Finken MJJ. Nutritional programming by glucocorticoids in breast milk: targets, mechanisms and possible implications. Best Practice \& Research. Clinical Endocrinology \& Metabolism 201731 397-408. (https://doi.org/10.1016/j.beem.2017.10.001)

28 Yehuda R, Daskalakis NP, Bierer LM, Bader HN, Klengel T, Holsboer F \& Binder EB. Holocaust exposure induced intergenerational effects on FKBP5 methylation. Biological Psychiatry 201680 372-380. (https://doi.org/10.1016/j.biopsych.2015.08.005)

29 Loi M, Sarabdjitsingh RA, Tsouli A, Trinh S, Arp M, Krugers HJ, Karst H, van den Bosch R \& Joëls M. Transient prepubertal mifepristone treatment normalizes deficits in contextual memory and neuronal activity of adult male rats exposed to maternal deprivation. eNeuro 2017 4. (https://doi.org/10.1523/ENEURO.0253-17.2017)

30 Arp JM, Ter Horst JP, Loi M, den Blaauwen J, Bangert E, Fernández G, Joëls M, Oitzl MS \& Krugers HJ. Blocking glucocorticoid receptors at adolescent age prevents enhanced freezing between repeated cueexposures after conditioned fear in adult mice raised under chronic early life stress. Neurobiology of Learning and Memory 2016133 30-38. (https://doi.org/10.1016/j.nlm.2016.05.009)

31 Papilloud A, Veenit V, Tzanoulinou S, Riccio O, Zanoletti O, de Suduiraut IG, Grosse J \& Sandi C. Peripubertal stress-induced heightened aggression: modulation of the glucocorticoid receptor in the central amygdala and normalization by mifepristone treatment. Neuropsychopharmacology 201944 674-682. (https://doi.org/10.1038/ s41386-018-0110-0)

32 Ding J, da Silva MS, Lingeman J, Chen X, Shi Y, Han F \& Meijer OC. Late glucocorticoid receptor antagonism changes the outcome of adult life stress. Psychoneuroendocrinology 2019107 169-178. (https:// doi.org/10.1016/j.psyneuen.2019.05.014) 
33 Joëls M \& De Kloet ER. Effects of glucocorticoids and norepinephrine on the excitability in the hippocampus. Science 1989245 1502-1505. (https://doi.org/10.1126/science.2781292)

34 Phuc Le P, Friedman JR, Schug J, Brestelli JE, Parker JB, Bochkis IM $\&$ Kaestner KH. Glucocorticoid receptor-dependent gene regulatory networks. PLOS Genetics 20051 e16. (https://doi.org/10.1371/ journal.pgen.0010016)

35 Karten YJ, Nair SM, van Essen L, Sibug R \& Joëls M. Long-term exposure to high corticosterone levels attenuates serotonin responses in rat hippocampal CA1 neurons. Proceedings of the National Academy of Sciences of the United States of America 199996 13456-13461. (https://doi.org/10.1073/pnas.96.23.13456)

36 Ozbakir B, Crielaard BJ, Metselaar JM, Storm G \& Lammers T. Liposomal corticosteroids for the treatment of inflammatory disorders and cancer. Journal of Controlled Release 2014190 624-636. (https://doi.org/10.1016/j.jconrel.2014.05.039)

37 Meijer OC, Koorneef LL \& Kroon J. Glucocorticoid receptor modulators. Annales d'Endocrinologie 201879 107-111. (https://doi. org/10.1016/j.ando.2018.03.004)

38 Coghlan MJ, Jacobson PB, Lane B, Nakane M, Lin CW, Elmore SW, Kym PR, Luly JR, Carter GW, Turner R, et al. A novel antiinflammatory maintains glucocorticoid efficacy with reduced side effects. Molecular Endocrinology 200317 860-869. (https://doi. org/10.1210/me.2002-0355)

39 De Bosscher K, Vanden Berghe W, Beck IME, Van Molle W, Hennuyer N, Hapgood J, Libert C, Staels B, Louw A \& Haegeman G. A fully dissociated compound of plant origin for inflammatory gene repression. Proceedings of the National Academy of Sciences of the United States of America 2005102 15827-15832. (https://doi.org/10.1073/ pnas.0505554102)
40 Miner JN, Ardecky B, Benbatoul K, Griffiths K, Larson CJ, Mais DE, Marshke K, Rosen J, Vajda E, Zhi L, et al. Antiinflammatory glucocorticoid receptor ligand with reduced side effects exhibits an altered protein protein interaction profile. Proceedings of the National Academy of Sciences of the United States of America $2007 \mathbf{1 0 4}$ 19244-19249. (https://doi.org/10.1073/pnas.0705517104)

41 Schäcke H, Berger M, Rehwinkel H \& Asadullah K. Selective glucocorticoid receptor agonists (SEGRAs): novel ligands with an improved therapeutic index. Molecular \& Cellular Endocrinology 2007 275 109-117. (https://doi.org/10.1016/j.mce.2007.05.014)

42 Zalachoras I, Houtman R, Atucha E, Devos R, Tijssen AMI, Hu P, Lockey PM, Datson NA, Belanoff JK, Lucassen PJ, et al. Differential targeting of brain stress circuits with a selective glucocorticoid receptor modulator. Proceedings of the National Academy of Sciences of the United States of America 2013110 7910-7915. (https://doi. org/10.1073/pnas.1219411110)

43 van den Heuvel JK, Boon MR, van Hengel I, Peschier-van der Put E, van Beek L, van Harmelen V, van Dijk KW, Pereira AM, Hunt H, Belanoff JK, et al. Identification of a selective glucocorticoid receptor modulator that prevents both diet-induced obesity and inflammation. British Journal of Pharmacology 2016173 1793-1804. (https://doi.org/10.1111/bph.13477)

44 Desmet SJ \& De Bosscher K. Glucocorticoid receptors: finding the middle ground. Journal of Clinical Investigation 2017127 1136-1145. (https://doi.org/10.1172/JCI88886)

45 Koorneef LL, van den Heuvel JK, Kroon J, Boon MR, 'tHoen PAC, Hettne KM, van de Velde NM, Kolenbrander KB, Streefland TCM, Mol IM, et al. Selective glucocorticoid receptor modulation prevents and reverses nonalcoholic fatty liver disease in male mice. Endocrinology 2018159 3925-3936.

Received 17 July 2019

Revised version received 20 August 2019

Accepted 17 September 2019 